\title{
Der Randeffekt
}

\author{
Eine Feblerquelle beim OUCHTERLONY-Test
}

Von R. KIRST

Aus dem Institut für Gerichtliche Medizin der Humboldt-Universität Berlin (Direktor: Prof. Dr. med. babil. O. Prokop)

(Eingegangen am 19. November 1965)

\begin{abstract}
In den dem Plattenrand nahen Agargelbezirken formieren sich im OuchrerLoNY-Test auf Glasplatten bei gleicher Beschickung ausgestanzter peripherer Rosettenblätter asymmetrische Präzipitationsfiguren.
\end{abstract}

In the OUCHTERLONY test on glass plates, asymmetric precipitation patterns are formed in the area of the agar gel near to the edge of the plate, when basins arranged in a peripheral rosette are also loaded.

Die von ÖrJAN OuchterLoNy im Agargel eingeführte Immunodoppeldiffusion $(1,2)$ hat sich als spezifische, hochempfindliche Nachweismethode für Eiweiße oder deren Komponenten schon vielfach bewährt. Sie wird zu qualitativen, weniger zu quantitativen Analysen herangezogen. Insbesondere in Kombination mit der Elektrophorese hat sie der modernen serologischen Forschung neue Wege zur Aufklärung der Antigenstruktur der Eiweiße gebahnt. Nach dieser Technik können wir, wenn präzipitierende Antikörper und homologe Antigene auf ihrer Diffusionsbahn einander begegnen, eine spezifische Eiweißfällung erwarten, die allerdings erst bei Erreichen der kritischen Schwellenkonzentration beider Reaktionspartner sichtbar wird. Entsprechend den Berührungsstellen der Diffusionsflächen formiert sich dann ein gerades oder gebogenes Präzipitationsband. Für die richtige Deutung des Präzipitationsbildes erweisen sich optimale Versuchsbedingungen als außerordentlich wichtig. Wir möchten noch kurz auf die im Schrifttum mitgeteilten Hinweise eingehen $(3,4)$. So ist jedem Antigen-Antikörper-Komplex nur dann eine einzelne, unabhängige Präzipitationslinie zugeordnet, wenn äquivalente Konzentrationen vorhanden sind, d. h. die Molekulargewichte annähernd übereinstimmen und damit gleiche Diffusionskoeffizienten vorliegen. Weichen dagegen die Mengenverhältnisse vom Äquivalenzspektrum ab, entwickeln sich gekrümmte, undeutliche Fällungsbilder mit sekundären Phänomenen, und es kommt zur partiellen, ja sogar völligen Auflösung der AntigenAntikörper-Verbindungen (5-9) - alles Erscheinungen, die eine genaue, zuverlässige Ablesung der Präzipitationsstreifen erschweren oder gänzlich unmöglich machen. Es würden breitere oder schmalere, längere oder kürzere, dichtere oder lockere, mehr oder minder verschwommene Fällungsspuren entstehen. Sekundäre Präzipitate stellen eine Unterbrechung einfacher Bilder dar, wobei sich die Bogen an den Enden wieder treffen sollten; sie sind unspezifisch und täuschen dem ungeübten Beobachter weitere Antigene vor. In der Literatur werden sie als „immunologische Artefakte“, „periodische Präzipitate" oder Liesegangsche Bänder" bezeichnet. Aufgelöste Niederschläge treten beim R-Typ der Antikörper (rabbit antibody, horse anti-poly-saccharide, horse $\gamma$ globulin anti-protein) nur bei Antigenüberschuß auf, während sie beim H-Typ (horse $\beta$-globulin antiprotein) auch bei Antikörperüberschuß beobachtet werden. Es ist bekannt, daß die von Kaninchen stammenden Antikörper ein kleineres Molekulargewicht haben und weniger häufig zu sekundären Präzipitationen neigen als die schwe1eren, vom Pferd gewonnenen Antikörper (4). Hiernach zu urteilen, müßte man praktisch zum Ausschluß unechter Linien erst in Vorversuchen die optimale Antigen-Antikörper-Konzentration suchen.

Wir beobachteten nun bei orientierenden Untersuchungen recht unterschiedliche Ergebnisse, obwohl der Antigen-Antikörper-Spiegel gleich hoch gewählt war. Wir arbeiteten mit sieben verschiedenen, unverdünnten $\mathrm{Ka}$ ninchen-Immunseren und beliebigen, ebenfalls unverdünnten menschlischen Seren, verwendeten phosphatgepufferte Agargel-Glasplatten $(\mathrm{pH}=7,2 ; \mu=0,5$; $M=0,1$ ) vom Format $13 \times 18 \mathrm{~cm}$, die in üblicher Weise mit ausgehobenen rosettenförmigen Mustern, etwa $16-20$ an der Zahl, versehen waren. In die zentrale Rundung jeder Rosette hatten wir pro Platte dasselbe Immunserum eingefüllt. Die peripheren Reservoirs beschickten wir mit verschiedenen menschlichen Serumproben. Nach einer Zeit von 1 bis zu 4 Tagen bei Zimmertemperatur hatten sich, auch iñ 'parallel angesetzten Versuchșeihen bei $+4^{\circ}$, an den dem Plattenrand zugewandten Antigensitzen regelmäßig schärfere und intensivere Präzipitationsbänder entwickelt (Abb. 1). Oft zeigen sich, allerdings abhängig vom Immunserum, zwei oder auch mehrere, sogenannte periodische, teils an den Enden verbundene, teils scheinbar selbständige Streifen als bei den der Plattenmitte zugekehrten Antigenplätzen sowie bei allen nicht gerade am Plattenrand gelegenen Rosetten. Gleichartige Resultate erbrachte die Beladung der sechs peripheren Agarschalen einer Rosette mit jeweils derselben Serumprobe bei stets auf jeder Platte denselben Antiseren in den zentralen Reservoirs. Ein sehr interessantes Bild entwickelte sich nun, als wir eine Umkehr in der Füllung der Oucbterlony-Rosetten vornahmen. Obwohl auch jetzt alle sechs Rosettenblätter gleich versorgt waren, allerdings mit Immunserum - wobei wir in das Zentrum eine Serumprobe als Antigen gaben - bildeten sich bei den randständigen Rosetten keine einheitlichen Ringfiguren, sondern asymmetrische Präzipitate. Hier zweigte sich zum Plattenrand hin der sonst kräftige und sehr deutliche einzelne Präzipitationsbogen in mehrere, zunehmend an Dichte 

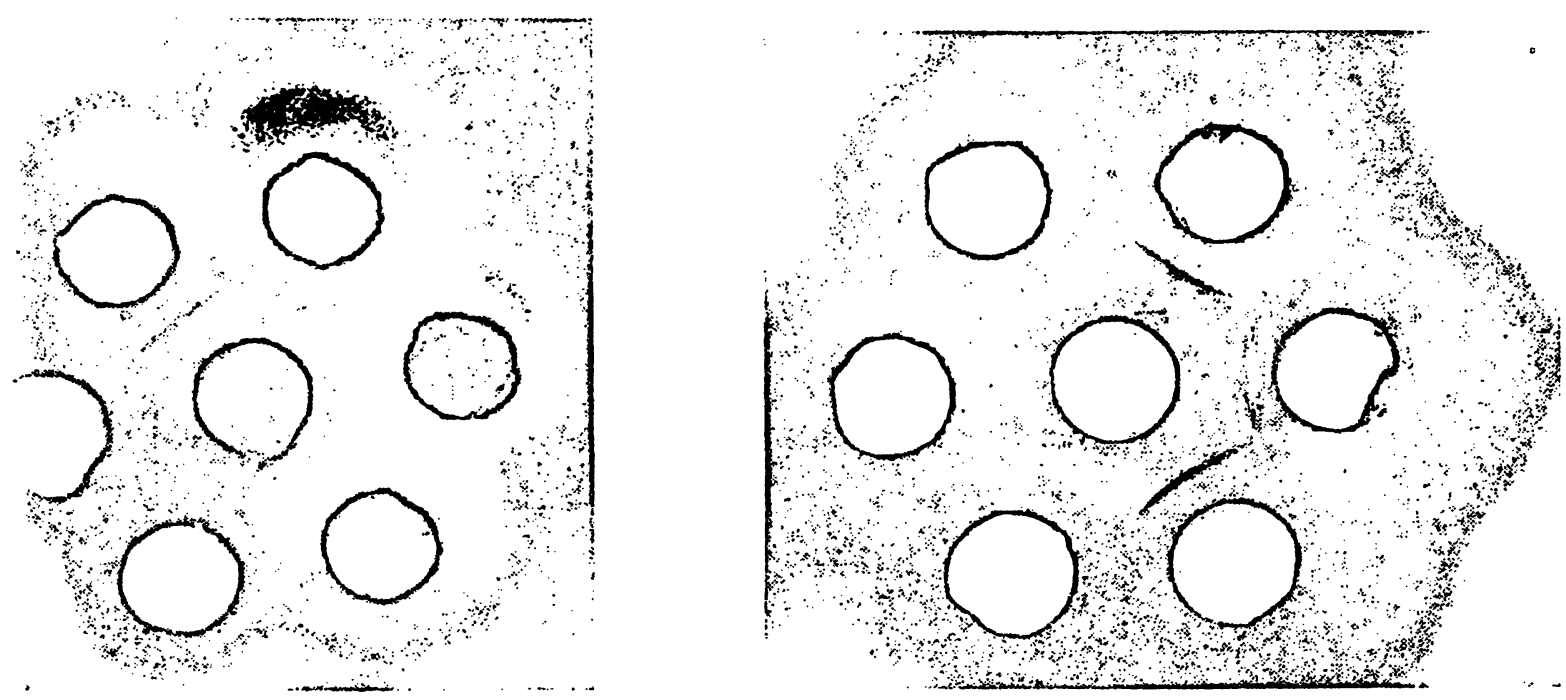

Abb. 1

Ausschnitte aus einer mit 18 OUCHTERI.ONY-Rosetten besetzten Glasplatte vom Format $13 \times 18$. Dargestellt sind die in den oberen Ecken (links und rechts) gelegenen Rosetten mit dem leicht erkennbaren Randeffekt

verlierende, stärker gekrümmte Spuren auf bis er manchmal vollständig verlosch. Wir wählten für diese eigenartigen, stets in Nähe des Plattenrandes dargestellten Phänomene die Bezeichnung Randeffekt. Interessanterweise zeigte sich bei allen sogenannten Randeffekten, unabhängig von der Beschickung der Rosette, eine Verschiebung bzw. eine Verzerrung der Präzipitationsfigur nach außen, so daß sich eine größere Weglänge zum Rosettenkelch bzw. ein kürzerer Abstand zum Rosettenblatt hin bei den randnahen Agarbezirken ergibt als bei den mehr im Platteninnern gelegenen Feldern. Desgleichen waren die Diffusionshöfe um die Rosettensäume in exzentrischer Art nach außen verzogen, während wir in Plattenmitte schöne konzentrische Wanderungsbilder erblicken konnten. Aus diesen Beobach- tungen leitet sich eine beschleunigte Randdiffusionsströmung ab, die mit einer Konzentrationsabnahme des in Richtung Rosettenzentrum wandernden Reaktionspartners verbunden ist. Der hier offenbar vorliegende Dosis-Effekt hängt wahrscheinlich mit der stärkeren Oberfächenkrümmung der Agargelschicht zum Glasplattenrand hin zusammen. Da sich nur bei Beschickung der Rosetten-Randlöcher mit Antikörpern eine Abschwächung bzw. eine Auflösung der Antigen-Antikörper-Komplexe darstellte, und die PräzipitationsStreifen bei den antigenbeladenen peripheren Rosettenschalen, die dem Plattenrand abgewandt lagen, schwächer und undeutlicher waren, könnte dies nur durch einen Antigenüberschuß erklärt werden.

\section{Literatur}

1. Ouchiterlony, Ö., Acta pathol. microbiol. scand. 32, 231 (1953). - 2. Ouchterlony, Ö., Progr. Allergy 5, 1 (1958). - 3. Crowle, A. J., Ann. Rev. Microbiol. 14, 161 (1960). - 4. Crowle, A. J., Immunodiffusion. Academic Press New York and London (1961). - 5. Jennings, R. K., J. Immunology 77, 156 (1956). - 6. KA-
MINsKr, M., Bull. Soc. Chim. biol. 36, 279 (1954). - 7. KAMrnsskr, M., Bull. Soc. Chim. biol. 36, 289 (1954). - 8. Korngold, L. und G. VAN LEEUWEN, J. Immunology 78, 172 (1957). - 9. SCheidEgGer, J. J., Int. Arch. Allergy Appl. Immunol. 7, 103 (1955).

Dr. Renate Kirst

Institut für Gerichtliche Medizin der Humboldt-Universität Berlin X 104 Berlin

Hannoversche Str. 6 